\title{
NUMERICAL MODELING OF SHOCK-INDUCED DAMAGE FOR GRANITE UNDER DYNAMIC LOADING
}

\author{
H. A. Ai ${ }^{1}$ T. J. Ahrens ${ }^{1}$ \\ ${ }^{1}$ Lindhurst Laboratory of Experimental Geophysics, Seismological laboratory, \\ California Institute of Technology, Pasadena, CA, 91125.
}

\begin{abstract}
Johnson-Holmquist constitutive model for brittle materials, coupled with a crack softening model, is used to describe the deviatoric and tensile crack propagation beneath impact crater in granite. Model constants are determined either directly from static uniaxial strain loading experiments, or indirectly from numerical adjustment. Constants are put into AUTODYN-2D from Century Dynamics to simulate the shock-induced damage in granite targets impacted by projectiles at different velocities. The agreement between experimental data and simulated results is encouraging. Instead of traditional grid-based methods, a Smooth Particle Hydrodynamics solver is used to define damaged regions in brittle media.
\end{abstract}

Keywords: granite, JH2 model, crack softening, shock-induced damage, AUTODYN, SPH.

PACS: 91.60.-x, 91.60.Ba.

\section{INTRODUCTION}

Shock-induced damage in rocks beneath impact craters is useful for constraining the impact history $[1,2]$. The behavior of rocks to dynamic loading is very complex. Cracks from impact events are induced by both shear and tensile failure. In the high pressure region ahead of a projectile during impact process, the inelastic shear straining dominates the production of damage. For region at low pressure, the principal tensile stress is of the same order as the deviatoric stress. Tensile cracks would be produced in this region. However, a complete and appropriate constitutive model to describe deformation and damage of rocks due to both components is still needed for numerical simulation.

We apply JH-2 model, which was originally developed by Johnson and Holmquist for ceramics [3], to geological crustal rocks for the first time. A crack softening model is coupled with $\mathrm{JH}-2$ model to represent the tensile cracks generation [4]. We focus on how to determine model parameters for granite. We put these parameters into AUTODYN$2 \mathrm{D}$ [5] to calculate the damage that occurs beneath and surrounding impact craters in crustal rocks. The simulated results are also compared with experimental data.

\section{DETERMINATION OF MODEL CONSTANTS FOR GRANITE}

The JH-2 constitutive model assumes that the strength of material, both intact and fractured, is dependent on pressure, strain rate, and damage. The dependence of strength on these parameters is represented by a set of constants. These constants are derived from standard dynamic and quasi-static measurements [3].

A summary of these constants for granite is listed in Table 1. The following will discuss how to determine the constants for pressure, strength, damage, as well as crack softening. 
Table 1: JH-2 baseline and crack softening constants for granite.

\begin{tabular}{ll}
\hline Strength constants & \\
Hugoniot elastic limit (HEL) & $\mathrm{HEL}=4.5 \mathrm{GPa}$ \\
HEL Strength & $\sigma_{\mathrm{HEL}}=2.66 \mathrm{GPa}$ \\
HEL Pressure & $P_{\mathrm{HEL}}=2.73 \mathrm{GPa}$ \\
HEL Volumetric Strain & $\mu_{\mathrm{HEL}}=0.045$ \\
Tensile Strength & $T=0.15 \mathrm{GPa}$ \\
Normalized Tensile Strength & $T^{*}=0.055$ \\
Intact Strength Coefficient & $A=1.01$ \\
Intact Strength Coefficient & $N=0.83$ \\
Strain Rate Coefficient & $C=0.005$ \\
Fracture Strength Coefficient & $B=0.68$ \\
Fracture Strength Exponent & $M=0.76$ \\
Maximum Fracture Strength & $\sigma_{f}^{*}=0.2$ \\
Pressure Constants & \\
Bulk modulus & $K_{l}=55.6 \mathrm{GPa}$ \\
Pressure coefficient & $K_{2}=-23 \mathrm{GPa}$ \\
Pressure coefficient & $K_{3}=2980 \mathrm{GPa}$ \\
Bulking factor & $\beta=1.0$ \\
Damage constants & \\
Damage coefficient & $\mathrm{D} 1=0.005$ \\
Damage exponent & $\mathrm{D} 2=0.7$ \\
& \\
Cracking Softening Constants & \\
Tensile failure stress & $T_{f}=0.15 \mathrm{GPa}$ \\
Fracture energy & $G_{f}=70 \mathrm{~J} / \mathrm{m}^{2}$ \\
\hline
\end{tabular}

\section{Pressure}

Fig. 1 shows the axial stress, $\sigma_{l}$, and the mean

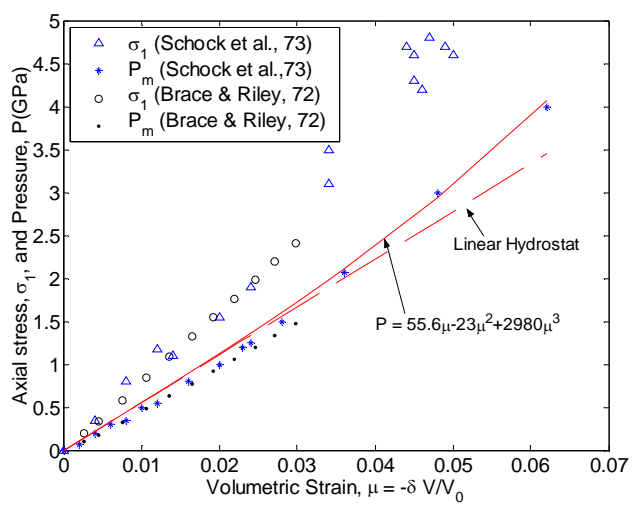

Figure 1: Test data and model for shock pressurevolume response of granite. stress/pressure, $P$, as a function of the volumetric strain $\mu$ during uniaxial strain loading for Westerly granite [6] and for Climax stock granodiorite [7]. Pressure constants $K_{1}, K_{2}, K_{3}$ are obtained by fitting $P$ to $\mu$ using

$$
P=K_{1} \mu+K_{2} \mu^{2}+K_{3} \mu^{3},
$$

where $K_{l}, K_{2}$, and $K_{3}$ are constants $\left(K_{l}\right.$ is the bulk modulus), and $\mu=\rho / \rho_{0}-1$ for current density $\rho$ and initial density $\rho_{0}$. The linear hydrostat is also shown to provide a reference.

\section{Strength}

The HEL is taken as $4.5 \mathrm{GPa}$, the average value from [8]. We follow the method described in [3] to determine the strength and pressure components at HEL. The HEL volumetric strain is solved from $H E L, K_{1}, K_{2}, K_{3}$, and $G$ as $\mu_{H E L}=0.045$. Substitute $\mu_{H E L}$ into Eqn. 1 gives pressure at HEL of $P_{H E L}=$ 2.73 GPa. The equivalent stress, defined as twice of the material shear strength, at HEL is $2.66 \mathrm{GPa}$ $\left(\sigma_{H E L}\right)$. The intact equivalent stress of the material as a function of pressure, from data in Fig. 1, is shown in Fig. 2. Also shown is the calculated value from JH-2 model using constants in Table 1 at two strain rates, $10^{5} \mathrm{~s}^{-1}$ and $10^{-4} \mathrm{~s}^{-1}$. It seems that the effect of strain rate is rather small. The strain rate coefficient, $C$, is assumed to be 0.005 , taken as the same as ceramic [3]. Fortunately, this constant does not influence the result greatly.

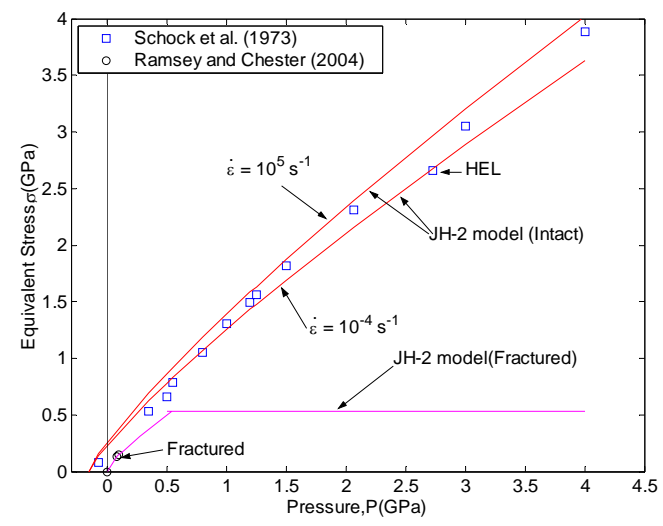

Figure 2: Test data and model for strength of intact and damage granite. 
The dynamic tensile strength of San Marcos granite is $0.13 \mathrm{GPa}$, determined by planar impact method described in [2, 9]. Similar procedure gives $P_{\text {tensile }}=-0.067 \mathrm{GPa}$ and $\sigma_{\text {tensile }}=0.08 \mathrm{GPa}$ (Fig. 2). Extrapolating this to $\sigma=0$ gives tensile strength $T=-P_{\sigma=0}=0.15 \mathrm{GPa}$. The normalized tensile strength is $T^{*}=T / P_{H E L}=0.055$. Intact strength constants $A$ and $N$ are obtained by nonlinear fitting of the experimental data using:

$$
\sigma_{i}^{*}=A\left(P^{*}+T^{*}\right)^{N},
$$

$\sigma_{i}^{*}$ is the normalized equivalent stress.

No proper fractured strength data for granite are found. Instead, some fractured data for marble are used for this purpose. The source of the fractured data shown in Fig. 2 is from [10]. We fit the data available to Eqn. 3 to obtain the fracture strength constants, $B$ and $M$.

$$
\sigma_{f}^{*}=B\left(P^{*}\right)^{M}
$$

More experiments for fracture strength of granite are necessary to obtain a better constraint of these fractured strength parameters. The normalized fractured strength is limited not to exceed the maximum fractured strength, $\sigma_{f_{\text {max }}^{*}}^{*}$, taken as 0.2 here, or $0.53 \mathrm{GPa}$ as the equivalent stress.

\section{Damage}

Damage $(D)$ describes the transition from intact to fractured strength. Under a constant pressure, damage begins to accumulate when the material begins to flow plastically $(D=0)$. When the material is completely damaged, $D=1$. The damage parameters $D_{1}$ and $D_{2}$ used by Johnson and Holmquist [3] are not directly measurable. Instead, numerical adjustment is applied to obtain $D_{l}$ and $D_{2}$ listed in Table 1.

\section{Tensile crack softening}

The maximum principal tensile stress for the tensi- le softening model is $0.15 \mathrm{GPa}$, as noted above. The associated fracture energy is assumed to be 70 $\mathrm{J} / \mathrm{m}^{2}$, which is the value obtained for ceramics [4].

\section{EXAMPLE}

The determined constants for granite are put into AUTODYN-2D to simulate two impacts into granite by a lead bullet and copper ball. Parameters for projectile are retrieved from AUTODYN library [5]. The calculated results are presented and compared with experiment data.

\section{Lead bullet impacting granite}

Simulation of a $3.2 \mathrm{~g}$ lead bullet impacting a 20x20x15 cm granite block at $1200 \mathrm{~m} / \mathrm{s}$ is carried out. Radius of the projectile is $3 \mathrm{~mm}$. The meshfree Smoothed Particle Hydrodynamics (SPH) solver [5] is used for the projectile and rock target, with smoothing particle size to be $0.125 \mathrm{~mm}$ for the projectile and $0.25 \mathrm{~mm}$ for the target. The geometry of the problem setup and the response of target are assumed to be axisymmetric.

The simulated final damage profile is compared with the experimental result (Fig. 3). The crater depth is $\sim 1.5 \mathrm{~cm}$, and crater diameter is $\sim 7 \mathrm{~cm}$, both of which agree well with the experiment. The prediction of radial tensile cracks is encouraging: the pattern of simulated tensile cracks for both situations is very similar with the experiment. And the tensile cracks extend to 6-7 $\mathrm{cm}$ for both cases.

Simulations with and without the crack softening model were carried out and compared. The tensile cracks when the crack softening model is not included do not extend as long as that when the model is included.

\section{Copper ball impacting granite}

Comparison between calculation and experiment for a copper ball ( $0.64 \mathrm{~cm}$ in radius) impacting a granite block at impact velocity of $690 \mathrm{~m} / \mathrm{s}$ is shown in Fig. 4. Again, the agreement is very good. The crater depth is $\sim 1 \mathrm{~cm}$, crater diameter is $\sim 5 \mathrm{~cm}$, and tensile cracks extend to $\sim 8 \mathrm{~cm}$ for both cases. 


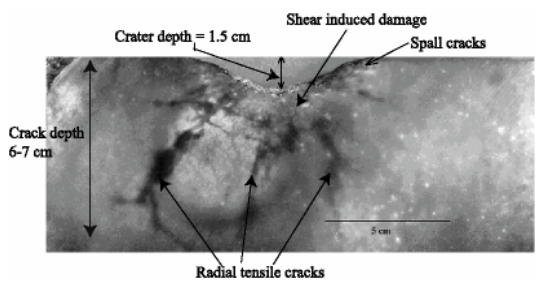

(a)

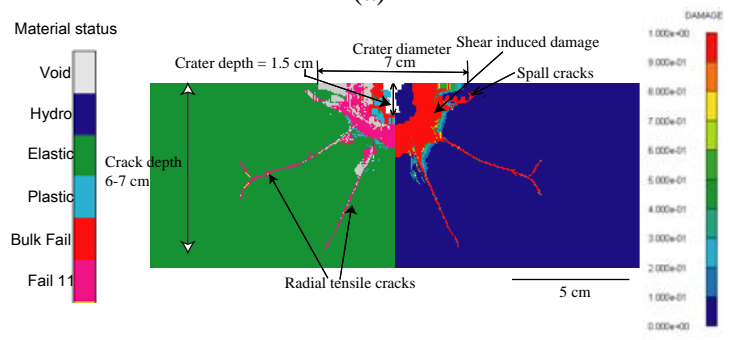

(b)

Figure 3: Cross section of granite impacted by lead bullet at $1200 \mathrm{~m} / \mathrm{s}$ illustrating crack distribution. (a) Experimental result; (b) AUTODYN-2D simulation at $0.03 \mathrm{~ms}$. Left panel illustrates material status; right panel illustrates damage.

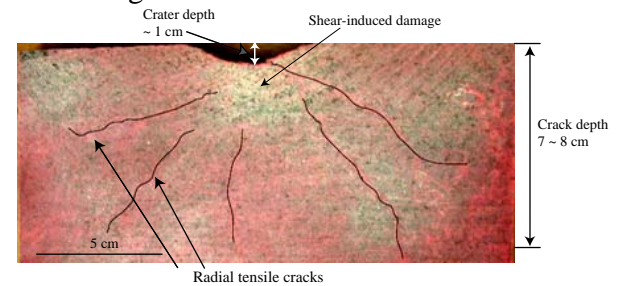

(a)

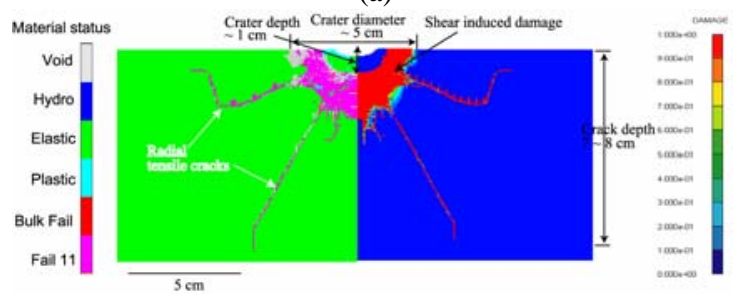

Figure 4: Cross section of granite impacted by copper ball at $690 \mathrm{~m} / \mathrm{s}$. (a) experimental result; (b) simulation at $0.04 \mathrm{~ms}$. Others are the same as in Fig. 3b.

\section{CONCLUSION}

This work is intended to describe response of geological material under impact loading. The JH-2 constitutive model describing mechanical character of brittle material, coupled with a crack softening model, is applied to granite for the first time to represent the deviatoric and tensile cracks produced beneath an impact crater in rocks. Model constants are obtained either from direct static measurement, or from indirect numerical calibration. The agreement between the calculation and experiment is encouraging.

\section{ACKNOWLEDGEMENTS}

Research supported by NASA/Goddard grant under award no. NNG04GI07G. Contribution No. 9123. Division of Geological and Planetary Sciences, Caltech.

\section{REFERENCES}

1. Ahrens TJ, Xia K, Coker D, "Depth of cracking beneath impact craters: New constraint for impact velocity", in Shock-compression of condensed matter, 2002 (MD. Furnish, LC. Chhabildas, RS. Hixson, eds.), pp. 1393-1396.

2. Ai HA, Ahrens TJ, "Dynamic tensile strength of terrestrial rocks and application to impact cratering," Meteoritics \& Planetary Science 39(2), 233-246, 2004.

3. Johnson GR, Holmquist TJ, "Response of boron carbide subjected to large strains, high strain rates, and high pressures," J. Applied Phys 85(12), 80608073. 1999.

4. Clegg RA, Hayhurst CJ., "Numerical modeling of the compressive and tensile response of brittle materials under high pressure dynamic loading", in Shock compression of condensed matter, 1999 (MD. Furnish, LC. Chhabildas, RS. Hixson, eds.) pp. 321-324.

5. AUTODYN Theory manual. 2003.

6. Brace WF, Riley DK, "Uniaxial deformation of 15 rocks to $30 \mathrm{~kb}$ ", Int. J. Rock. Mech. Min. Sci. 9, 271-288, 1972.

7. Schock RN, Heard HC, Stephens DR, "Stress-strain behavior of a granodiorite and two graywackes on compression to 20 kilobars", J. Geophys. Res. 78, 5922-5941, 1973.

8. Petersen CF, "Shock wave studies of selected rocks," Stanford Univ. Ph. D. thesis, p. 99. 1969.

9. Ahrens TJ, Rubin AM, "Impact-induced tensional failure in rock," J. Geophys. Res. 98, 1185-1203. 1993.

10. Ramsey JM, Chester FM, "Hybrid fracture and the transition from extension fracture to shear fracture," Nature 428(6978), 63-66. 2004. 